\title{
Strategies for Facilitating Learning Support Processes. What can Teachers do Support Learners with Specific Learning Difficulties?
}

\author{
Mubi F. Mavuso \\ Department of Inclusive Education \\ University of South Africa (UNISA), PO Box 392 Pretoria 0003 \\ mavusmf@unisa.ac.za
}

\section{Doi:10.5901/mjss.2014.v5n2p455}

\begin{abstract}
Inclusion of learners with diverse learning difficulties in the mainstream schools is a global phenomenon. The stance to accommodate learners with diverse learning needs demand teachers to be competent in implementing learning support processes to ensure that learners learn optimally. Although several countries like South Africa are in favor of inclusion, teachers seem to battle in providing learning support for learners presenting with specific learning difficulties. A qualitative interpretive research was conducted to explore and describe the experiences of senior phase teachers in selected mainstream schools. Purposive sampling included senior phase teachers who are members of the School Based Support Teams. Data was collected through individual and focus group interviews; document analysis; and field notes which were reflected in a journal. This article discusses the findings extracted from interviews on learning support strategies used by teachers. According to the teachers learning support strategies include: Giving learners extra work and re-teaching; differentiation; assessment; peer support and referring learners.
\end{abstract}

Keywords: Learning support, inclusion, specific learning difficulties.

\section{Introduction}

Inclusion reached its impetus at the world Conference on Special Needs Conference in 1994 in Salamanca Spain to promote inclusive education (UNESCO 1994, p. 7). The goal for inclusion was to promote the objective of education as fundamental human right and enabling schools to serve all learners including those with special educational needs (UNESCO 2009, p. 8).

The stance for inclusion therefore requires teachers to be competent in using a variety of teaching strategies; selecting specific teaching and learning material, displaying an inviting attitude and collaborating with parents and other stakeholders. In practical terms, teachers are expected to identify specific difficulties experienced by learners, develop intervention programmes to support learner and where applicable refer learners for additional support. Learning support is thus seen as one of key areas to fulfill education for all.

The Department of Basic Education (DBE) uses the concept 'learning support' to refer to a process of removing barriers that may hamper learning (DoE, 2001, p.17, DBE, 2010), with support seen as enhancing learning through interacting with appropriate support providers (DoE, 2003, p.23). For Bouwer (2005, p.48), learning support is a collaborative approach to addressing the needs of learners experiencing barriers. Magare, Kitching and Roos (2010, p.55) prefer to use the phrase 'supporting learners', as referring to emotional nurturing, building positive relationships as well as communicating openly in a trusting manner. In this article, 'learning support' is used to refer to a collaborative process of identifying learning difficulties, and the development and implementation of intervention programmes using the curriculum, such as special concessions, curriculum differentiation and adaption, in order to support learners experiencing learning difficulties. Learning support also includes an appropriate referral system within the school, with other relevant stakeholders and the broader society. It includes referral to the district office and appropriate placement of learners.

\section{Literature Review: Contextualizing Learning Support for Learners Presenting with Specific Learning Difficulties in the Mainstream Schools in South Africa}

Learning difficulties are common in schools but present themselves differently, and it is important that teachers address 
them as they inhibit learning. Farrell (2004, p.17) asserts that 'learning difficulties', 'learning disabilities', 'special needs' and 'barriers to learning' are concepts used interchangeably, with a learner experiencing them if he or she progresses more slowly in school or whose academic performance is poorer than the majority of children of his or her age, or has a disability which either prevents or hinders him or her from making use of educational facilities generally provided for other children.

Donald, Lazarus and Lolwana (2010, p.278) use the term 'specific learning difficulties' as a collective concept that refers to conditions such as communication, emotional, and other specific learning difficulties which do not have a clearly identifiable basis and are subject to different social contexts. They warn that to refer to such conditions as 'difficulties' would neither be accurate nor helpful to those concerned. When referring to the concept 'intellectual disabilities' they propose that the term refers to a general problem which is experienced in the broad areas of understanding, remembering, reasoning and other higher cognitive functions and claim it to be one of the most urgent areas of need ( p.310).

For the purpose of this article, the concept 'learning difficulties' is preferred and will be used to refer to learners experiencing specific difficulties in acquiring basic literacy skills, who have significant language difficulties and whose academic achievement is below their potential. The concept also include learners who struggle to learn and are failing in schools, those who progress more slowly in terms of academic performance, have specific learning difficulties that are less readily identifiable, do not always have a clear physical basis, and are more subject to different social contexts.

This article addresses strategies used by teachers in providing learning support for learners presenting with Specific Learning Difficulties (SpLD) in four mainstream schools. Selected participants had interacted with the phenomena being learners presenting with SpLD difficulties as subject teachers, coordinators of the SBST, learning support educators in the senior phase (Grades 7-9).

In South Africa, most learners presenting with specific learning difficulties are accommodated in the mainstream schools and are supported inclusively (DoE 2001, 2008, 2010). Donald et al. (2010, p.287) write that accommodating learners in less restrictive environments means that those with specific learning needs should, wherever possible and with appropriate support, be educated alongside others through the regular school and curriculum. They state that:

\footnotetext{
"... the right for all children whatever their disability or difficulty, should be seen and treated as normally as possible and (not labeled or separated); the right of all children to have their individual needs met within the regular school system as far as this is possible; and the right of all children to live at home, attend local school, and lead as normal as possible".
}

Therefore, the Norms and Standards for Educators stipulates that teachers should be qualified, competent, dedicated, and caring (DoE 2000, p.4). Teachers are therefore required to fulfill roles of being mediators of learning, interpreters and designers of learning programmes and materials, leaders and administrators, scholars, researchers, lifelong learners, community members, citizens and pastors, assessors and subject specialists (DoE, 2000, p.4). For Ackah $(2010, p .35)$, teachers are thus considered the key players as well as actors in making inclusive education succeed.

Supporting the views highlighted by (Naicker 2005), who state that in prior to 1994 separate training programmes did not provide trainees in the mainstream education system with experience to develop necessary skills and dispositions to handle learners with disabilities, I contend that teachers in the mainstream schools are ill equipped to provide leaning support resulting in most learners being inappropriately supported on time.

As a researcher who previously worked in Inclusion and Special Schools unit at district office of the Gauteng Department of Education, I had encountered an alarming number of referrals of learners between the ages of 14 and 18 who presented with significant language difficulties and were unable read and write in their African languages as well as in English, yet they were continually promoted from the Foundation Phase (Grades 1-3) through the Intermediate Phase (Grades 4-6) until the Senior Phase (Grades 7-9). In many instances, learners were only identified, retained and referred to the Inclusison and Special Schools when they were in grade 7 and 9.

This situation occurred inspite of attempts by the DBE in exposing teachers to learning support processes through training on policies such as the Education White Paper 6 - Special Needs Education: Building Inclusive Education and Training (EWP6) (DoE, 2001), the national Strategy for Screening, Identification, Assessment and Support (SIAS) was launched as an attempt to strengthen the implementation of EWP6 (DBE, October 2008). Therefore, the situation suggested that a gap existed in what the availabity and training of teachers on learning support processes as well as the practical implenetation of such policies. 


\title{
3. Research Methodology
}

A qualitative research approach was utilized to explore, and describe the experiences of teachers who provide learning support for learners presenting with specific learning difficulties in the senior phase mainstream schools. Purposeful sampling (Henning 2007) included senior phase teachers composed of referring teachers, School Based Support Teams coordinators and Learning Support Educators. A phenomenological research design type was used to understand the meaning teachers attach to providing learning support for learners presenting with specific learning difficulties in mainstream schools (De Vos, Strydom, Fouche and Delport 2007, p.264, Creswell 2007, p.27). Data was collected through semi- structured individual and focus group interviews, document analysis and field notes (Henning 2004 Gravett, \& Vanrensberg, Merriam 2009). Data was analyzed through thematic content analysis, breaking down data into manageable sections and analyzing it (De Vos 2009).

\section{Findings, and Discussions - Strategies Used by Senior Phase Teachers in Providing Learning Support}

Participants were asked to describe their experiences on strategies they used to provide learning support. This article reports on the following strategies extracted from both individual and focus group interviews: giving learners extra work, re-teaching, peer support, assessment, and referring learners. The article also integrates literature control.

\subsection{Give learners extra work, translate the work and re-teach as a learning support strategy}

This section captures extracts depicting participant's conceptions of "giving learners extra work" and re-teaching as strategies for facilitating learning support processes. Most participants expressed similar ideas regarding giving learners extra work, translating the lessons and re-teaching as a strategy for providing learning support. Selected extracts include the following:

\begin{abstract}
We support them by giving them extra work, sitting with them after school, eh..., with some of them and then we call all of them and sit with them and try to find out where they have difficulties.
\end{abstract}

\begin{abstract}
Because some learners find it difficult to understand what is expected when they read, I try to translate, give the learner examples, the similarities, and the opposite of the words [antonyms] you know, for the learner to understand what the vocabulary is. I try to translate the vocabulary with the learner and I try to simplify the work for the learner"
\end{abstract}

\footnotetext{
What I will do is that, after school maybe learners will stay behind, and I will explain that thing again, give them examples, work out an example with them, give them some work to go and try at home. Tomorrow they must come and show me
}

There is a teacher who gives extra lessons in the afternoon. Besides, the teacher is based at the school to give learners some support

This particular sub-theme illustrates that teachers do have mechanism that they use in an attempt to provide learning support. I also gathered that they were aware of some of the classroom practices and referral systems, as well as referral processes expected in providing learning support. However, the point related to giving extra work as a learning support strategy could imply different understanding of what learning support means. In addition, that one teacher equated extra work with expanded opportunities could also be open to different interpretations of reflected by learning support policies. In my view, giving extra work to a learner who is struggling with the content of a particular learning area can create anxiety as well as contribute to low self-esteem. This may require a review of training processes by policy mediators from the provincial and district level of the DoE.

The Strategy for Identification Assessment and Support (DBE, 2008) suggests that teachers use individualized support plans as a mechanism to support learners experiencing learning difficulties. This policy guideline further states that such plans should be implemented by individual teachers. Additional steps to be used include various interventions, assistive devices, peer support and environmental adaptions.

\subsection{Differentiation as a strategy to provide learning support}

Participants were aware about differentiation and preferred to use the concept multi-level teaching as a strategy that 
could be used for accommodating learners experiencing learning difficulties. Their interpretation include varying teaching styles, teaching at a lower grade and setting aside time to focus on a particular learner. I noted that most participants who referred to this learning support strategy were those teachers who had more teaching experience compared to those with lesser teaching experience. Selected extracts include:

Sometimes I would lower the complexity of the lesson, maybe that particular question, then tell the person [learner] to try that and then the next time, I will pick up the level in class or maybe during school hours, maybe during that period, I will see that child. Maybe if I am not busy, I will go to that child and then ask her, "are you okay?"

\begin{abstract}
Multilevel teaching eh..., it accommodates learning diversity because learners have their own way of leaning. Some are visually strong, some are auditory strong, some are kinaesthetic and some are tactile strong. So teachers need to introduce activities that will involve multisensory approach so that everyone will be involved in that activity because some will be cutting, some will be moving around in class and some will be doing calculations but will be focused on the same assessment standard
\end{abstract}

\begin{abstract}
I always change my style of teaching basics, putting the sentence there, change part of the speech and putting it somewhere to make it easier for them to understand

For those who have problems, I make a point that I go below and I write sight word so that at least they can read those words on a wall daily and I bring newspapers and then we read
\end{abstract}

Those who are bright, I encourage them to go on with their work and then work with those who need support. I work with them especially and over the weekend.

Literature reveals that differentiated teaching is a concept embraced in inclusive education and it denotes to a process which attempt at using different methods and approaches to accommodate different learning difficulties (Walton 2012, p.118). Differentiated teaching is often used interchangeable to refer to multilevel teaching. In South Africa, differentiated teaching is encompassed in policies such the Curriculum Assessment Policy Statement National (CAPS) which recommends that it should be used when planning the curriculum so as to optimize the strength and aptitude of the learners as well as a process of making inclusion a reality (DBE 2010). Walton (2012, p.118-120) advises that differentiated teaching enables learners to experience success, it prevents learning gaps, provides opportunities for cognitive development and reduces challenging behaviour in the classroom.

For Bornman and Rose (2010), differentiated teaching is viewed as an effective strategy in diverse classrooms as it aims to ensure that each learner has individualized learning outcomes that may be set at different levels below within the same curriculum area. They propose that differentiated teaching involves establishing how learners can access the curriculum, finding entry points and using complex instruction which allow learners to explore several entry points to the topic. In using this skill, they recommend that teachers should try to match the teaching of the content with different learning styles. Furthermore, in differentiating, the curriculum is compacted ensuring that learners are identified and their results are examined, planning for the learning with scaffolding is used, aided language stimulation, the product, setting learning contracts, alternative forms of assessment and giving learners homework.

\title{
4.3 Assessment of learners a strategy to provide learning support
}

Assessment is viewed as an integral part of teaching and learning. Its purpose of includes gathering information about the learner for use in planning. Assessment also reflects information about the learner in terms of what he or she knows, understands, what the learner is able to do, as well as how he or she learns (DBE, 2008). It ensure learners experiencing learning difficulties are accommodated assessed inclusively through various forms and encourages teachers to use special concessions in order to create a favourable assessment environment, as well as processes that cater for the needs of the learner (DoE, 2001, DBE, 2008, 2010).

Participants also reported that they use assessment as learning support strategy. It is important to note that those who directly stated this sub-theme were mostly Learning Support Educators, whilst others implied that they were using assessment practices without mentioning the concept directly. Nevertheless, participants did not mention specific assessment processes used to accommodate learners experiencing learning difficulties, such as special concessions, despite encouragement to do so by the DBE. This is significant as teachers are the first people who should be able to implement such an assessment process, which forms part of learning support processes. Selected extracts relating to this sub-theme include: 
Normally we assess the learners. We assess the learners' skills and all those using whole language approach where we do speaking, reading and writing activities with the child and find out how far is the child, what are the child' specific problems and re-group everything with what is causing the problem .

Sometimes if it is a task that they have done or they have not done properly, we teach the task and help them re-do again. We then assess the learners to see if they understand

Nel, Nel \& Hugo (2012, pp.48-54) assert that assessment cannot be a once off when it is used for determining the barriers experienced by learners. They recommend that focus be on the learners' strengths not weaknesses, as well as on other interactions and influences in the learner's life. In their view, assessment should be dynamic, a view also expressed by the DoE (2005). Several assessment types, include baseline, formative, summative and diagnostic assessments that Nel et al. (2012, p.51).

As Bouwer $(2005,2011$, p.56) states, before teachers can conduct assessment they should consider the four component principles of process, person, content and time. By so doing they will have an opportunity to look at the developmental level of the learner and understand the influence and relevance of the context within which the child is learning. One would therefore consider aspects such as the family, school, peer group and community, whilst understanding the learners' proximal process of interaction with their environment as necessary underpinning for interpreting of performance results.

Furthermore, Bouwer (2011, p.56) asserts that this understanding assists in searching for and mustering support from a broader perspective, including the learner's life world, unlike a narrower approach which focuses on only one intervention. The scholar states that before teachers can conduct assessment they should consider the four component principles of process, person, content and time. By so doing they will have an opportunity to look at the developmental level of the learner and understand the influence and relevance of the context within which the child is learning. This scholar $(2005,2011$, p.56) advises that before teachers can conduct assessment they should consider the four component principles of process, person, content and time. By so doing they will have an opportunity to look at the developmental level of the learner and understand the influence and relevance of the context within which the child is learning.

\subsection{Peer support a strategy to provide learning support}

Peer support intervention is viewed as creating social participation and other learning experiences in which learners interact with each other. Viewed as one of the learning support strategies, participants indicated that they use peer support to address specific language related difficulties experienced by learners.

Selected extracts from the interviews include:

Sometimes you invite the learner who speaks the same language of the learner who has the problem to be a sort of mediator between you and the learner so that you know that the problem could be particularly solved. That's what we normally do, but this is being done by the school. It is sort of a norm that we practice.

I realized that they [learners] understand their peers than me when I am in class. So, I put them in groups according to their multi-level of intelligence

I use peer support especially when it comes to reading. Those who can read better, I give them a learner to go outside with them and practice how to read.

Lerner and Kline (2006, p.115) consider peer tutoring as a concept that could be used for learning support, describing it as a strategy that encourages two learners to work together on a particular task. One learner serves as a learner while the other serves as a tutor, with a particular skill being taught and learnt.

For Carter and Kennedy (2006, p.284) peer support is a valuable strategy that can be used to promote access to general curriculum for learners with severe disabilities. They argue that students with disabilities should benefit from alternate assessment as well as support instruction as a way of accessing the curriculum meaningfully. Peer support interventions have a goal to increase both access and to facilitate social interactions in general settings.

In using peer support as a strategy, teachers should begin by selecting students who would act as peers, then training them in class activities; facilitating participation of students with disabilities; contributing to the development of the Individualized Education Plan goals; supporting behaviour intervention plans; providing frequent positive feedback; 
modeling age-appropriate and contextually relevant communication skills; and facilitating interaction with other learners.

In such a setting, information is tailored according to individual needs of a student with disabilities who will be supported by peers. Carter \& Kennedy $(2006$, p.286) stress that students do not necessary lose their individual support, but rather the process of implementing peer support is periodic and followed by monitoring by paraprofessionals, special education teachers and general educators.

Reflecting on selected extracts in this study, it is clear that teachers are using peer support as a strategy to address language difficulties expressed by learners, especially in settings where there are learners from foreign countries. I gathered from the research study on which this article is based that learners who were engaged as peer support were those who had been resident for longer in South Africa and had begun learning in English from the foundation phase. Learners who were reported to be struggling in English were those who had started their schooling in South Africa in the intermediate or senior phase.

Teachers from a school in which learners had migrated from other provinces within the country also reported using peer support, but not as much as those in schools in which the majority of learners were from neighboring African countries. However, it has not been established whether teachers planned to use this strategy. Although this is a case, the attempt by teachers to use peer support should be taken in a positive light as it indicates that teachers as mediators of learning do try to make sense of their context.

\section{Conclusion}

In this article I discussed a theme on strategies used by teachers to provide learning support for learners who present with specific learning difficulties in the mainstream schools. Selected sub-themes which were extracted from both individual and focus groups were discussed and elaborated with literature control.

\section{References}

Ackah, F.R. (2010). Teacher characteristics as a predictor of attitude towards inclusive education in the Cape Coast Metropolis of Ghana. IFE psychology LA, Vol 18: 35-47.

Babbie, E. \& Mouton, J. (2001, 2003, 2006, 2008). The Practice of Social Research. Cape Town: Oxford University Press.

Babbie, E. (2010). The Practice of Social Research, International Edition(12thEdition). USA: Wadsworth.

Bornman, J \& Rose, J. (2010). Believe that all can achieve. (Increasing classroom participation in children with special support needs). Pretoria (South Africa): Shumani.

Bouwer, C. (2005). Identification and assessment of barriers to learning. In Landsberg, E., Kruger, D. \& Nel. N. (Eds). Addressing Barriers to Learning. Pretoria: Van Schaik, 45-60.

Carter, E.W \& Kennedy, CH. (2006). Promoting Access to General Curriculum Using Peer Support. Journal of Research \& Practice for Persons with Severe Disabilities. 4. 284-292.

Carter, E.W \& Kennedy, CH. (2006). Promoting Access to General Curriculum Using Peer Support. Journal of Research \& Practice for Persons with Severe Disabilities. 4. 284-292.

Creswell, J.W. (2007). Qualitative inquiry and research designs: choosing among five traditions (2nd ed). Thousand Oaks: Sage.

Department of Education (DoE) (2001) Education White Paper 6. Special Needs Education: Building and Inclusive Education and Training System. Pretoria. Government Printers.

Department of Education (2008). National Strategy on Screening, Identification, Assessment and Support. Pretoria: Government Printers.

De Vos, A.S. Strydom, H., Fouche, C.B. \& Delport, C.S. L. (2005). (Eds) Research at Grassroots: For the social and human Service professions (Ed). Pretorias Van Schaik Publishers. 267-273.

Donald D., Lazarus, S. \& Lolwana, P. $(2006,2010)$ Educational Psychology in Social Context: Oxford University Press.

Engelbrecht, P. (2004). Changing roles for educational psychologists within Inclusive education in South Africa. School Psychology International. 26(1)20-29.

Engelbrecht, P. (2006). Promoting the implementation of inclusive education In South Africa. Pretoria: Van Schaik.

Farrell, M. \& Ainscow, M. (2002). Making special education inclusive. London: David Fulton.

Gauteng Department of Education. (2004). Manual for learner support educators. Pretoria: Government Printers.

Henning, E. Gravett, S \& Vanrensberg, W. (2004). Finding your way in academic writting. (2nd Edition). Pretoria: Van Schaik.

Henning, E. Van Rensburg, M. \& Smit, B. (2005). Finding your way in qualitative research. (3rd Edition). Pretoria: Van Schaik.

Index for Inclusion (2011). Developing learning and participation in school. Centre for studies on Inclusive Education: Supporting inclusion and challenging exclusion. Retrieved on February 10, 2011 from http://www.csie.org.uk/resources /inclusion-indexexplaines.html.

Isaksson, J., Lindqvist, R. \& Bergstrom, E. (2010). Pupils with special education needs: A study of assessment of and categorising process regarding pupils' school difficulties in Sweden. International Journal of Inclusive Education. (4) 2,Routledge Tailor and 
Francis.

Jooste, C. \& Jooste, J. (2011). Intellectual impairment. In Landsberg, E., Kruger, D. \& Swart, E. (2011). Addressing barriers to learning: A South African perspective. (2nd edition) Pretoria: Van Schaik, 417-445.

Landsberg, E. Kruger, D. \& Swart, E. (2005). Addressing Barriers to Learning: A South African Perspective: Van Schaik.

Magare, L., Kitching. A., \& Rose, V. (2010). Educators' experiences of inclusion learning context: an exploration of competencies. $A$ South African Journal of Perspective in education. Vol 28 (52-63).

Merriam, S.B. (2009) Qualitative Research: A Guide to design and implementation. U.S: Library Cataloguing in Publication Data.

Naicker, S. (2005a). From policy to practice. A South African perspective on the implementation of inclusive education. International Journal of whole schooling 3(1): 1-6.

Nel, N., Nel, M.N., \& Hugo, A. (2012). A Learner support in a diverse classroom: A guide for Foundation, Intermediate and Senior Phase teachers of language and mathematics.

UNESCO. In: Landsberg, EL \& Gericke, C. (2006). Quality Education for All. Pretoria. University of South Africa.

Walton, EW. (2012). Learner Support through differentiated teaching and learning, in Nel, N, Nel, MN, \&Hugo, A. (2012) Learner support in a diverse classroom: A guide for Foundation, Intermediate and Senior Phase teachers of language and mathematics. 117-139. 
